\title{
Spatial Differentiation of Urban Housing Prices in Guangdong Province and Its Influencing Factors
}

\author{
Fei Chen \\ School College of Economics, Jinan University, Guangzhou, China \\ Email: lujiajia719@163.com
}

How to cite this paper: Chen, F. (2018) Spatial Differentiation of Urban Housing Prices in Guangdong Province and Its Influencing Factors. Modern Economy, 9, 664-681.

https://doi.org/10.4236/me.2018.94043

Received: March 9, 2018

Accepted: April 21, 2018

Published: April 24, 2018

Copyright $\odot 2018$ by author and Scientific Research Publishing Inc. This work is licensed under the Creative Commons Attribution International License (CC BY 4.0).

http://creativecommons.org/licenses/by/4.0/

\section{(c) (7) Open Access}

\begin{abstract}
In the context of the central government's policies on housing prices themed on "adjust measures to local conditions and classifying macro-control", it is of great significance to study the convergence and the differences of housing prices. Taking the urban area of Guangdong province as an economic unit, this paper explores the spatial heterogeneity of housing price in Guangdong Province during 1995-2014 and the spatial heterogeneity of its impact factors by means of ESDA and GWR models. The study found that the spatial structure of housing prices in the region shows a certain circle structure, while the housing prices in the Pearl River Delta region are relatively high, there is a big difference in housing prices between Zhongshan, Huizhou and other cities. In most of the cities in eastern, western and northern Guangdong, the price of housing is low, which is extremely different from the price of housing of cities in the Pearl River Delta, there is also a huge difference between the housing price of Shantou and that of its surrounding cities. The influencing factors of housing prices in different cities show a localized characteristic of unbalanced linkage. The difference between the impact of GDP per capita and the floor space of buildings completed on housing prices is the largest in the two time sections. In the middle and late time of the real estate development, the relevancy degree between housing prices and GDP per capita is no longer obvious, and is more affected by the urbanization rate and population migration, especially in western Guangdong. The completion of housing area and loan balance has the greatest sensitivity to urban housing prices in western Guangdong. The former has the least sensitivity to the Pearl River Delta region. The latter has the least sensitivity to housing price in eastern Guangdong Province. The amount of the investment in real estate development has the greatest sensitivity to Meizhou, Chaozhou, Shantou and Jieyang prices produced the largest inhibition effect, the inhibition effect of the western part of
\end{abstract}


the smallest. Therefore, we should combine the current situation of housing prices in different regions with the spatial effect mechanism of impact factors and promote the healthy development of real estate economy according to local conditions. The main contribution of this paper lies in: Firstly, for the first time we use ESDA-GWR model to systematically analyze the evolution of city level characteristics and spatial correlation of Guangdong Province and the spatial difference of impact factor driving prices fluctuation, as well as to solve the problem of regional differentiation regulation policies provide the basis. Secondly, we use the theory of real estate cycle to analyze the difference between demand and supply factors of housing prices in driving the fluctuation of housing prices in different cities, which provides the basis for adopting differentiated short-term and long-term regulatory policies and regional regulation and control policies. But there are also the limitations of Guangdong Province.

\section{Keywords}

Housing Price, Spatial Difference, ESDA-GWR Model

\section{Introduction}

At the end of last century, China's housing reform had led to rapid development of the real estate industry. However, with the subsequent urbanization and long-term loose monetary policies as well as the promotion of local governments, real estate rapidly developed into a pillar industry of the national economy. The housing price in the first and second has surged rapidly. Behind the phenomenon of the prosperous real estate economy, there is also a huge imbalance in regional development. As a result, the unified national real estate regulatory policy became more outdated. In May 2016, the CPC Central Committee Political Bureau proposed that "To digest real estate inventory orderly, pay attention to solve the regional, structural problems, and implement differential regulation and control policies", then the central bank put forward the policy of "according to the principle of in the light of local conditions, and government different cities with suitable measures, and in accordance with local conditions, due to the principle of urban policy, and further improved the regional differential housing credit policy", differential credit policy further confirmed by related agency at the central level, China's real estate policy began to implement the policy of "To government cities in accordance to local conditions, and control in a classified way". The introduction of the policy is based on the differences in the spatial distribution of urban commercial housing prices, showing real estate prices of different spaces are not the same. This article attempts to use 21 cities in Guangdong Province as different locations to analyze the spatial pattern and development rules of the housing prices in different cities, to reveal whether the spatial distribution of the housing price has shown homoplasy or difference, as 
well as discussing the mechanism of the influence factors of housing price on different spatial positions to provide empirical basis for the relevant department to the long-term regulation of the real estate market on the basis of "governance by local condition, and control in a classified way", which is a new field in real estate economic research.

The basic framework of this paper is as follows:

1) Using ESDA model to analyze the spatial distribution pattern of house prices in 21 cities in Guangdong Province, and using the global spatial autocorrelation and local spatial autocorrelation method to verify the existence of spatially positive correlations in housing prices, and to prove that there is a difference in the spatial distribution of housing prices.

2) In order to further analyze the difference in house prices, this paper applies local weighted least-squares method to introduce spatial distance to establish geographically weighted regression model (GWR) to analyze the influence factors of house prices in 21 cities of Guangdong Province in 2005, 2010 and 2014.

\section{Literature Review}

At present, the domestic and foreign scholars' research on house prices can be roughly divided into two categories: one is to build a theoretical model [1]; the other is to pay attention to the empirical analysis to explore the influencing factors of house prices, including demand-side factors [2], supply-side factors [3] and prospective factors. The real estate market is regional, and there are spatial linkages between housing prices in cities of that region. The American scholar Pollakowski et al. [4] think that the interdependence of inter-city dwelling prices decreases with increasing distance. In the distant cities, the spatial interaction of dwelling prices may exist or not. The empirical study of Pede [5] using spatial vector autoregression models proved that there is a significant spatial spillover effect between different urban housing prices, and the changes of variables such as income or population in neighboring cities will also impact the housing prices. Nowadays, the research on the housing price in China using the method of space measurement mainly focuses on the following aspects: The first one is to prove that there is a significant spatial effect on the fluctuation of house prices [6] [7] [8]. The second is to explore the influencing factors of housing prices spatially [9]. From the results of the existing research, the spatial metrology model may have advantages over the traditional OLS, the change of the spatial pattern of housing prices is actually more complex than the simple diffusion model. Third, the regional differences and house price fluctuations in the real estate market [10] [11] proved that the urban housing prices in China have obvious spatial relevance, but at the same time there are obvious regional differences, not only that. Housing prices in cities will also be affected by housing prices and income in neighboring cities. Longying [12] used a geographical weighted regression model (GWR) to analyze the factors affecting the fluctuation of house prices in China. From the angle of regional difference, this paper 
also analyzes the spatial heterogeneity of housing price fluctuation in different regions. Many domestic scholars use GWR model to explore the influence of different factors on housing price and its spatial difference [13]. Step by using exploratory data analysis (ESDA) combined with geographical weighted regression (GWR) and other spatial econometrics methods [14] [15], Zhang Jing et al. [16] constructed the GWR model of urban residential land price, and explored the spatial variation characteristics of influencing factors of urban residential land price in Jiangsu Province at three time points, 1997, 2005 and 2008 respectively. Which reveals the impact of various factors on the price of residential land and regional differences enriches and develops the spatial and temporal changes of urban land price factors of theoretical research.

At present, the ESDA-GWR model is used to study the spatial heterogeneity of the factors influencing housing prices fundamentals in cities, especially for the economically unbalanced regions like Guangdong Province. There are only a few researchers majoring in this topic. Firstly, for the first time we use ESDA GWR model to systematically analyze the evolution of city level characteristics and spatial correlation of Guangdong Province and the spatial difference of impact factor driving prices fluctuation, as well as to solve the problem of regional differentiation regulation policies provide the basis. Secondly, we use the theory of real estate cycle to analyze the difference between demand and supply factors of housing prices in driving the fluctuation of housing prices in different cities which provides the basis for adopting differentiated short-term and long-term regulatory policies and regional regulation and control policies.

\section{Data Description, Indicator Selection and Research Methods}

\subsection{Data Description}

All data are from the statistical yearbook of corresponding years in Guangdong Province and urban areas. Because the use of house price data in this paper adopts a 15-year time series length, since 1995, the real estate market in Guangdong Province has shifted from a planned economy to a market economy, gradually realizing the commercialization of housing. Therefore, the price data chose the average sales price of commercial buildings in 1995-2014 as the dependent variable. Since the price data of many cities are not published in the statistical yearbook of the province, while the total sales and sales area of commercial housing can be obtained from the statistical yearbook. The average sales price of commercial housing is obtained by dividing the total sales of commercial housing by the sales area of commercial housing. It should be noted that the reason that the author chose the average selling price of commercial housing to represent the city's housing prices is because that the city's housing price data is difficult to obtain, which, to a certain extent, reflects housing transaction volume in the real estate market, but may not really reflect the cities labor force commodity house paid acquisition cost, because in the statistical system of the cities, some demolished resettlement houses and affordable houses are also mixed in the calcula- 
tion of the total sales and area of commercial houses. This paper uses statistical software such as ArcGIS and Geoda to analyze the spatial dependence and heterogeneity of housing prices of various cities in Guangdong Province.

\subsection{Index Selected}

Short-term real estate is closely related to finance, and long-term real estate is related to population, short-term real estate is mainly affected by interest rates, mortgage down payment ratio, taxation, land policy and other financial policies, while short term real estate is mainly affected by economic growth, urbanization, and the size and structure of population. This article analyzes the fluctuation of house prices from long period and short period respectively. We select other exogenous control variables $(\mathrm{X})$ from the following aspects on the supply side: Based on the intensity of impact and the availability of data, we selected per capita GDP and urbanization rate from a variety of factors to reflect the impact of demand [17]. These two indexes reflect the impact on house price from the aspects of housing supply and housing supply cost respectively. In addition, the housing loan is very important to the development of the real estate market. The amount of credit mainly affects urban house prices in two ways. First, the amount of money is increased. Credit is an investment form in which financial institutions put loans on enterprises. It provides loans to enterprises for business management or investment, which increases the amount of money circulating in real life., thus promoting price increases, eventually causing prices to rise; Second, real estate developers in the early development period requires a lot of funds for turnover, financial institutions must be incorporated into the funds for operation, a large number of loans to real estate developers, the greater the total credit of a city The greater the amount of funds that flow into the real estate market, thus pushing up the price of housing. The amount of credit is measured by the balance of each city's loans. The greater the amount of credit, the higher prices are expected to increase faster. Therefore, this paper introduces the RMB loan balance as a part of the financial policy to influence the real estate market, summarizes the previous experience, on the basis of taking into account the availability of data, the correlation of various factors and the quality of indicators. Taking 21 prefecture-level cities in Guangdong Province as the research object, and based on the ESDA research on the correlation characteristics of the variables affecting the urban housing prices, a multivariate model of the geographical weighted regression regional housing prices and their influencing factors is constructed, using 5 indicators including $\mathrm{x} 1$ (per capita GDP), $\mathrm{x} 2$ (urbanization rate), $\mathrm{x} 3$ (completed house area), $\mathrm{x} 4$ (real estate development investment), $\mathrm{x} 5$ (loan balance) as independent variables.

\subsection{Research Methods}

\subsubsection{Spatial Weight Matrix}

The spatial weight matrix expresses the spatial layout of different spatial objects, 
such as the connection, topology and economic relations, which form the basis of the model. The specific form of the spatial weight matrix is:

$$
W=\left[\begin{array}{cccc}
w_{11} & w_{12} & \ldots & w_{1 n} \\
w_{21} & w_{22} & \ldots & w_{2 n} \\
\ldots & \ldots & \ldots & \ldots \\
w_{n 1} & w_{n 2} & \ldots & w_{n n}
\end{array}\right]
$$

where $n$ is the number of space units. If space unit $i$ and space unit $j$ is neighbor, then $w_{i j}=1$; otherwise, $w_{i j}=0$. A spatial unit does not neighbor to itself, which means $W_{i j}=0$. In general, we define whether the spatial unit $i$ and the spatial unit $j$ are neighbors based on two adjudication rules of adjacency relation and distance definition: if $i$ and $j$ have common edges or common points, they are considered as neighbor relationships. If the actual distance between $i$ and $j$ is within the set critical distance $d$ then they are considered neighbors.

\subsubsection{Global Spatial Autocorrelation}

The global spatial autocorrelation coefficient indicates the spatial correlation of observations in different regions of the entire study area. Methods to test global spatial autocorrelation include Moran's I, Geary C, and Getis' G, among which Moran's I is the most commonly used, with values ranging from -1 to 1 . When Moran's I is greater than 0 , There is a significant positive correlation between high observed values and high observed values. Low observed values tend to converge with low observed values, showing high or low concentration patterns. When Moran's I is less than 0 , it indicates that there is a significant negative correlation between observed values. High observed values tend to converge with low observed values, with high and low spatial heterogeneity. When Moran's I is close to 0 , Show that there is no spatial autocorrelation, the observations are randomly arranged in space. The formula is:

$$
\begin{gathered}
I=\frac{\sum_{i=1}^{n} \sum_{j=1}^{n} W_{i j}\left(x_{i}-\bar{x}\right)\left(x_{j}-\bar{x}\right)}{S^{2} \sum_{i=1}^{n} \sum_{j=1}^{n} W_{i j}} \\
Z=\frac{I-E(I)}{\sqrt{\operatorname{VAR}(I)}}
\end{gathered}
$$

In the formula, $S^{2}$ is the average variance of observation value, $x_{i}$ and $y_{i}$ are the observed values of I area unit and $j$ area unit, respectively, $W_{i j}$ is the element of the spatial weight matrix. In this paper, the adjacent standard $n$ is used as the number of study units, and here it is 21 . The $Z$ value is used to test whether there are spatial autocorrelations in n regions. When $Z$ is greater than 0 , it indicates that the observed values tend to gather in space. $Z$ is less than 0 and indicates that the observed values tend to be spatially scattered. When $Z$ is close to 0 , the observed value distributed randomly in an independent way. 


\subsubsection{Local Spatial Autocorrelation}

The local Moran's I index mainly studies the correlation between the characteristic values of the adjacent spatial units in the local area, and the formula is as follows (Wang Jinfeng et al., 2010):

$$
I_{i}=\frac{y_{i}-\bar{y}}{s^{2}} \sum_{j}^{n} w_{i j}\left(y_{i}-\bar{y}\right)
$$

where: for the local Moran's index, if $I$ is greater than 0 , the space presents a positive autocorrelation; $I$ is less than 0 , the space exhibits a negative autocorrelation; $I$ is close to 0 , on behalf of the absence of spatial autocorrelation, spatially random distribution.

The Moran scattergram is used to identify local spatial patterns, spatial outliers and local instabilities. The Moran scattergram can be divided into four quadrants, $\mathrm{HH}$ quadrant corresponding to high value agglomeration, LL quadrant corresponding to low value agglomeration, LH quadrant The corresponding low value is surrounded by a high value, the high value corresponding to the HL quadrant is surrounded by the low value. Based on the local Moran's I index, the Local Indicators of Spatial Association (LISA) method can be used to draw LISA cluster maps and LISA significance level maps. In the LISA cluster map, the spatial units with a significance level above 0.05 in local Moran's I index are classified into four spatial correlation types: low-low, high-high, low-high and high-low, The Relationship between Real Estate Economic Development and the Economic Development of Real Estate in Adjacent Cities.

\subsubsection{Geographic Weighted Regression Model}

Geo-weighted Weighted Regression (GWR) is a new method for studying the complexity, autocorrelation and variability of spatial data. The essence of GWR is the local weighted least-squares method, where the weight is the distance function between the geospatial location of the study area unit and the geospatial location of other units. In the GWR model, the regression coefficient is no longer a hypothetical constant, but a variable that is estimated by local regression using the neighboring attribute values and varies with the spatial position under a specific location. The GWR model is expressed as (6):

$$
y_{i}=\beta_{0}\left(u_{i}, v_{i}\right)+\sum_{j=1}^{n} \beta_{j}\left(u_{i}, v_{i}\right) x_{i j}+\varepsilon_{i}, \quad i=1,2, \cdots, m, \quad j=1,2, \cdots, n
$$

In forum (6), $\beta_{j}$ is the local coefficient of the variable $x_{i j}$ in the spatial position, which will change with the change of the spatial position $\left(u_{i}, v_{i}\right)$. In this paper, we use the GWR tool in ArcGIS10.2 software to set the model bandwidth by the commonly used AIC method and realize the modeling.

\section{Empirical Results and Analysis}

\subsection{Basic Overview of Housing Prices in Guangdong Province}

Before 1995, the real estate market in Guangdong Province, as a frontier area of reform and opening up, changed from a planned economy to a market economy 
and gradually realized the commercialization of housing. After the southern talks in 1992, real estate development and investment in Guangdong developed rapidly. The real estate industry has become an independent industry of initial scale. In 1995, the housing prices of Guangdong cities except Shenzhen were all below 5000 yuan $/ \mathrm{m}^{2}$. In 1995-2014, the housing prices in Shenzhen were always at the highest level, followed by Guangzhou, which began on 2005. The regional differences in housing prices in Guangdong Province are beginning to show. The growth rate of housing prices in Shenzhen is obviously higher than that in other cities in the province. Due to the relatively high degree of opening up to the outside world and the relatively high degree of mercerization of real estate in Shenzhen, by 2007, housing prices in Shenzhen were as high as 14,000 yuan per square. Housing prices in Guangzhou are only around 8600 yuan/square meter, in Zhuhai about 6400 yuan/square meter, in Dongguan and Foshan about 5000 yuan/square meter, and in other cities are under 5000 yuan/square meter. In 2008, affected by the subprime mortgage crisis in the United States, housing prices in Shenzhen slightly decreased but room for downward adjustment was not large. Policies such as lowering the down payment ratio and interest rates in 2009 stimulated the rapid recovery and warming of the real estate market. Shenzhen, Guangzhou, Zhuhai, Dongguan and Foshan prices to grow faster. In 2011, the house prices in Shenzhen reached as high as 20,000 yuan/square meter, the prices in Guangzhou and Zhuhai reached 10,000 yuan/square meter, followed by Foshan, Dongguan and Shantou, which was related to the development of urban economy. In developed areas, Guangzhou Shenzhen and real estate development scale, the pace of development in the PRD is ahead of other regions, especially in Shenzhen, the Pearl River Delta prices far more than the rest of the province, and the gap has widened. From this we can see that the regional differences in housing prices in Guangdong showed a gradual upward trend (Figure 1).

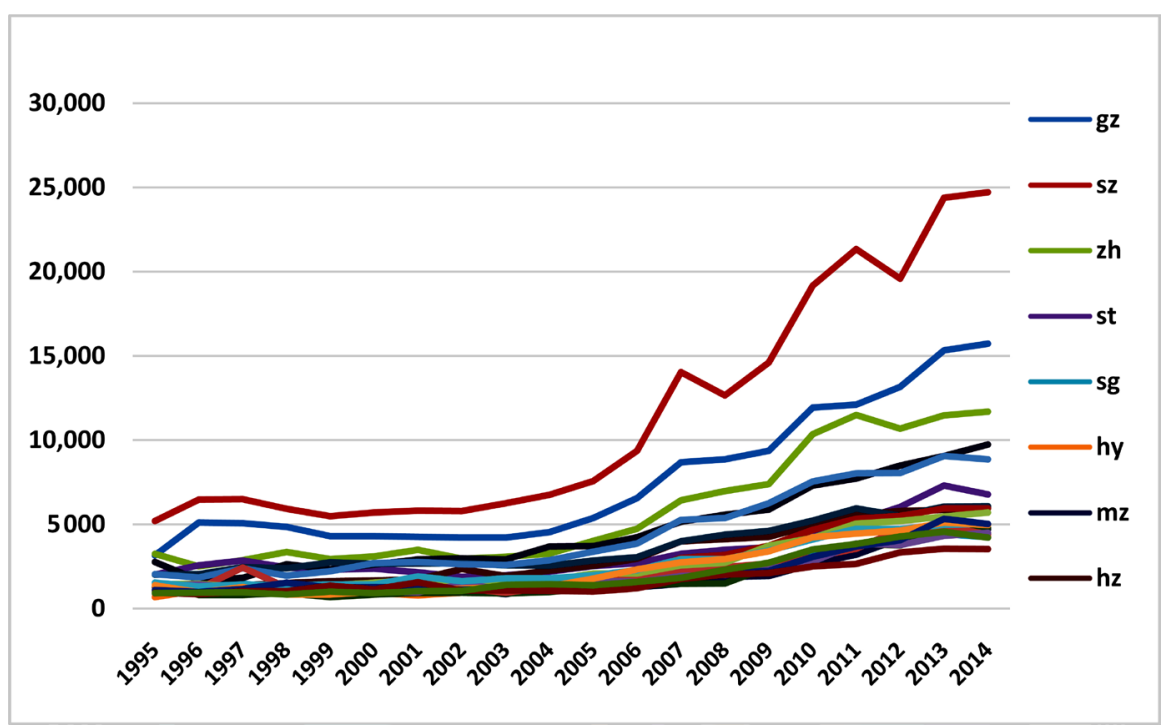

Figure 1. Trend of housing prices in Guangdong province from 1995 to 2014. 


\subsection{Spatial Bitmap Analysis}

In order to vividly show whether the housing prices in Guangdong Province have the characteristics of regional agglomeration, and whether the price distribution is consistent with the spatial location, the average sales price of commercial housing to reflect the fluctuations in housing prices, according to 1995-2014 Guangdong Province, total sales of commercial housing and Commercial housing sales area data, the use of ArcGIS 10.2 software for spatial bitmap analysis, the results shown in Table 1.

The results show that from the four phases of house price expansion in Guangdong Province (1995-2000, 2000-2005, 2010-2010, 2010-2014), the Pearl River Delta region centered around Guangzhou and Shenzhen is gradually formed, with Zhanjiang as the center In western Guangdong and eastern Guangdong, with Shantou as the center, housing prices have some characteristics of spatial analysis. Thus, the more developed the economy of the city is, the

Table 1. Space shares of cities in Guangdong province from 1995 to 2014.

\begin{tabular}{|c|c|c|c|c|}
\hline & 2000 & 2005 & 2010 & 2014 \\
\hline Guangzhou & 4294.11 & 5366.06 & $11,920.53$ & $15,718.64$ \\
\hline Shenzhen & 5717.99 & 7582.26 & $19,170.37$ & $24,723.23$ \\
\hline Zhuhai & 3102.08 & 4035.79 & $10,361.77$ & $11,697.57$ \\
\hline Shantou & 2363.48 & 2510.46 & 4276.51 & 6780.12 \\
\hline Shaoguan & 1089.47 & 1383.37 & 3238.26 & 4235.98 \\
\hline Heyuan & 939.92 & 1368.91 & 2838.03 & 4265.10 \\
\hline Meizhou & 1242.57 & 1161.79 & 2660.82 & 4698.07 \\
\hline Huizhou & 1675.94 & 2541.53 & 4960.52 & 5984.23 \\
\hline Shanwei & 837.34 & 1192.57 & 2857.42 & 4796.17 \\
\hline Dongguan & 2605.08 & 3709.77 & 7310.99 & 9735.87 \\
\hline Zhonshan & 2644.83 & 2857.11 & 5225.27 & 6072.99 \\
\hline Jiangmen & 1386.26 & 1912.40 & 4683.89 & 5949.92 \\
\hline Foshan & 2708.97 & 3385.65 & 7545.44 & 8861.91 \\
\hline Yangjiang & 1355.22 & 1449.18 & 3049.92 & 4408.69 \\
\hline Zhanjiang & 1535.67 & 2083.84 & 4192.94 & 5700.29 \\
\hline Maoming & 1041.40 & 1680.88 & 2796.65 & 4499.57 \\
\hline Zhaoqing & 1428.08 & 1973.66 & 4099.82 & 5022.92 \\
\hline Qingyuan & 1002.56 & 1785.67 & 4234.27 & 4970.09 \\
\hline Chaozhou & 1279.04 & 1387.89 & 3066.40 & 5013.97 \\
\hline Jieyang & 1156.24 & 1018.90 & 2507.43 & 3536.52 \\
\hline Yunfu & 910.64 & 1388.41 & 3513.15 & 4213.54 \\
\hline
\end{tabular}


higher the housing prices in the corresponding area will be.

From the perspective of the evolution of the real estate market, the spatial structure of housing prices in the region shows a certain cyclical structure. High-priced areas are gradually gathering in the Pearl River Delta. Prices in most cities in eastern Guangdong, western Guangdong and northern Guangdong are low, but the price difference between cities is not much difference, but the price difference with the Pearl River Delta city is very large. That is, cities with high housing prices gradually converge to the surrounding areas centered on Guangzhou and Shenzhen in the Pearl River Delta region. Cities with low prices gradually move away from the areas around Guangzhou and Shenzhen, and are located in the eastern, western and northern areas of Guangdong. Overall, the scale of the real estate market in Guangdong presents the phenomenon of bipolar aggregation in the region, and the difference in housing prices gradually increases, forming a circle structure in which housing prices in Shenzhen and Guangzhou are gradually expanding from high to low.

\subsection{Global Spatial Autocorrelation Analysis}

In this paper, we use Geoda software to analyze the global spatial autocorrelation of house price data of 21 cities in Guangdong Province. From Table 1, it can be seen that the spatial autocorrelation of housing prices in Guangdong Province fluctuated violently from 1995 to 1998. In 1996 and 1997, showing the positive spatial autocorrelation characteristics, the Moran's I coefficients were 0.046 and 0.043 , respectively, but the correlations were not large. This was due to the extremely immature development of the real estate market in China at that time. In 1995, after experiencing 1991-1995 Real estate speculation and regulation, the domestic real estate market is in a state of contraction. In 1998-2014, the positive spatial autocorrelation of housing prices in Guangdong Province was significant, the areas with similar prices (high-high or low-low) showed spatial agglomeration and spatial distribution. This is because in the face of the Asian financial crisis in 1998, the government started to implement the housing system reform, stop the physical distribution of housing, fully implement the housing distribution monetization policy, and at the same time establish and improve a multi-level housing supply system based on affordable housing and develop housing Finance, training and standardize the housing market, open the real estate development stage of gold. In 2002, 21 cities in Guangdong Province fully implemented the housing currency distribution plan, with the highest correlation coefficient. In 2004-2014, the positive spatial autocorrelation of house prices

in Guangdong Province gradually decreased, indicating that housing prices in the region as a whole showed a trend of dispersion.

All Moran's I values passed the 0.001 significance test, indicating that the housing prices in the Pearl River Delta region in Guangdong Province are relatively low and the housing prices in the non-Pearl River Delta region are relatively low, showing bipolar aggregation. Moreover, since 1997, the positive cor- 
relation has been increasing year by year Increase, and then reduce the band, the overall correlation is increased, the most relevant in 2002, and then gradually decreased, indicating that the overall trend of housing prices in 1997-2002 showed a trend of concentration in the region, but in 2002 Years later, Guangdong Province house prices in the region on the degree of concentration has decreased (Figure 2).

\subsection{Local Spatial Autocorrelation Analysis}

When using global spatial autocorrelation statistics to measure the spatial correlation between data, we can get that the spatial distribution of house prices in 21 cities in Guangdong Province is not completely random but shows a certain degree of spatial dependence. Since the result of the calculation is a single value, we do not know the degree of spatial variability at different locations. In order to further measure the spatial distribution of each area and the surrounding areas, the spatial differences and the distribution of spatial patterns, this paper uses the Moran scatter plot and LISA cluster map to make a spatial statistical analysis of the real estate industry in Guangdong Province (Table 2).

\subsubsection{Analysis of Moran Scatter Diagram}

In order to directly reflect the type and spatial distribution of spatial correlation

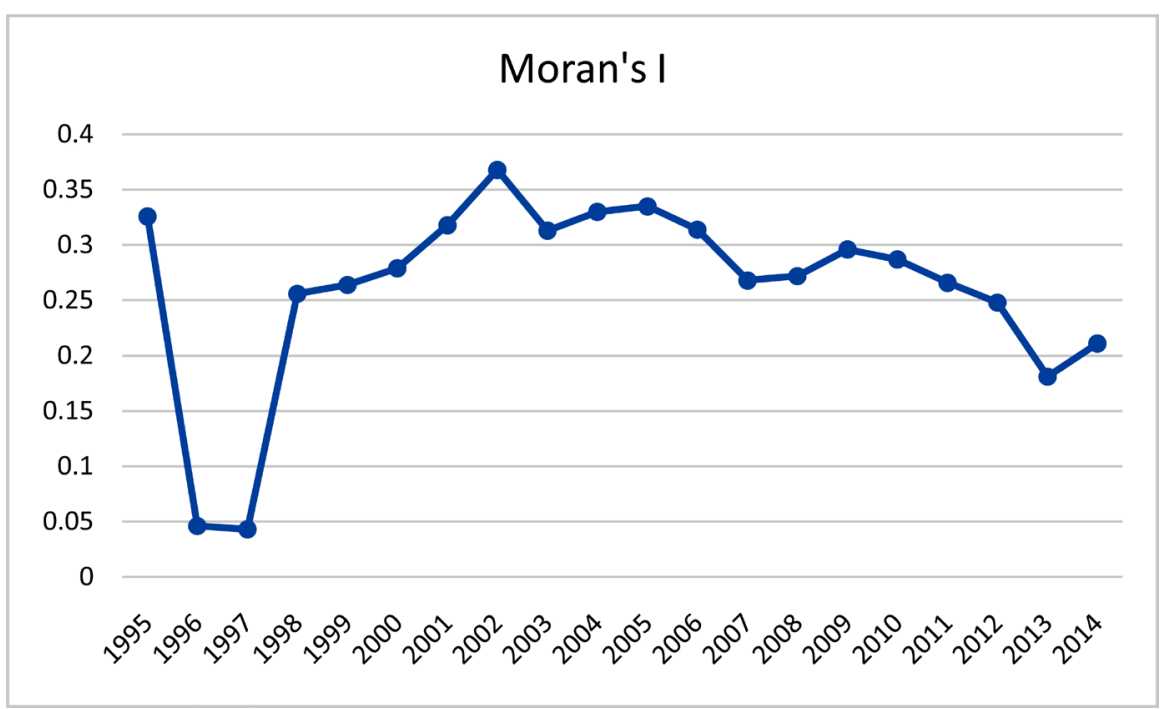

Figure 2. Moran's I coefficient of house prices in Guangdong Province, 1995-2014.

Table 2. House prices in each quadrant in 21 cities in Guangdong ( ${ }^{*}$ is significant).

\begin{tabular}{|c|c|c|c|c|c|}
\hline & 1995 & 2000 & 2005 & 2010 & 2014 \\
\hline LL & $\begin{array}{c}\text { zj mm yj yf hy mz } \\
\text { cz jy sw }\end{array}$ & $\begin{array}{l}\text { zq zj mm yj yf st } \\
\text { hy } \mathrm{mz} \text { cz jy sw }\end{array}$ & $\begin{array}{c}\text { zj mm yj yf hy* } \\
\mathrm{mz} \mathrm{cz}^{*} \text { jy sw }\end{array}$ & $\begin{array}{l}\text { zq zj mm yj yf st* } \\
\text { hy } m z^{*} \mathrm{cz}^{*} j y^{*} s w\end{array}$ & $\begin{array}{l}\text { zq zj mm yj yf st }{ }^{*} \\
\text { hy mz cz jy sw }\end{array}$ \\
\hline LH & hz $z^{*}$ jm qy sg zq & zs hz ${ }^{*}$ jm qy sg & jm qy sg zq & $\mathrm{zs}^{\star} \mathrm{hz}^{\star}$ jm qy sg & $\mathrm{zs}^{\star} \mathrm{hz}{ }^{\star} \mathrm{jm}$ qy sg \\
\hline HL & st & $s t^{*}$ & gz fs st* & $\mathrm{gz} \mathrm{fs}$ & fs \\
\hline $\mathrm{HH}$ & $\mathrm{sz}^{*} \mathrm{dg}^{*} \mathrm{gz}$ fs $\mathrm{zh}^{*} \mathrm{zs}^{*}$ & $\mathrm{sz}^{\star} \mathrm{dg} g \mathrm{z}^{*} \mathrm{zh}^{*} \mathrm{fs}$ & $s z d g z h^{*} z^{*} h z^{*}$ & $\mathrm{sz} \mathrm{dg}^{*} \mathrm{zh}^{*}$ & $\mathrm{sz} \mathrm{dg}^{*} \mathrm{gz} \mathrm{zh}^{*}$ \\
\hline
\end{tabular}


of housing prices in different cities, the Moran scatter plot of the average sales price of commercial housing in 21 prefecture-level cities of Guangdong Province from 1995 to 2014 was obtained by Geoda software, Spatial correlation type changes, a summary of the spatial evolution of housing prices in the city.

As shown in Table 2, from the four regions, most of the cities in eastern Guangdong and western Guangdong are in LL quadrant. Housing prices are generally low in the entire region, with the highest prices in Shantou in the eastern Guangdong region. In Guangzhou, Shenzhen, Prices in Dongguan, Foshan and Zhuhai are both high but unstable. Zhongshan, Huizhou, Jiangmen and Zhaoqing are in LH quadrant and LL quadrant, respectively. This shows that housing prices in the Pearl River Delta are high, but the gap between cities in the Pearl River Delta is relatively large, consistent with the phenomenon described above. However, most of Qingyuan and Shaoguan in northern Guangdong are in LH quadrant, while other cities are in LL quadrant, indicating that urban housing prices are high in Qingyuan and Shaoguan areas, but the scale of real estate development in northern Guangdong is generally low.

From the perspective of each quadrant, most of the prefecture-level cities and quadrants contained in the quadrants are relatively stable. There are a large number of prefecture-level cities in the first quadrant and the second quadrant, namely, there are two distinct types of HH quadrant and LL quadrant Binary structure shows the spatial heterogeneity in the region. Shenzhen and Dongguan are in the HH quadrant. Guangzhou, Foshan and Zhuhai straddle between the $\mathrm{HH}$ quadrant and the HL quadrant, indicating that the higher housing prices in Guangdong are concentrated in the PRD region. Zhanjiang, Maoming, Yangjiang, Yunfu, Zhaoqing, Heyuan, Meizhou, Chaozhou, Jieyang, Shanwei and other quadrants in the LL, indicating that Guangdong Province, lower housing prices concentrated in eastern Guangdong, western Guangdong and northern Guangdong, which verified the Guangdong Housing prices in the space showing the current situation of bipolar agglomeration, Qingyuan, Shaoguan, Zhongshan and Huizhou in the LH quadrant, but also reflects the housing prices there is a certain degree of spatial heterogeneity, due to the surrounding Guangzhou, Shenzhen, Foshan and Dongguan high-scale development of real estate The prefecture-level city.

\subsubsection{Lisa Analysis}

Since the Moran's I scattergram does not give a specific numerical value of the local significance of the market price of a city, it is necessary to further calculate the LISA saliency map of the local spatial autocorrelation and reflect the spatial correlation of the price between the neighboring cities in the local area, Thus in-depth discussion of the above spatial distribution pattern and the possible causes of geospatial. To this end, the spatial autocorrelation of spatial correlation LISA analysis (Anselin, 1995) is carried out on the city price as follows. In order to identify the spatial agglomeration pattern of housing prices in Guangdong from 2000 to 2014, this paper uses Geoda software to output the Moran saliency 
map of the average sales price of commercial buildings, and focuses on the significant spatial agglomeration.

As shown in Table 2, the prefecture-level cities included in each quadrant vary greatly. From the perspective of spatial heterogeneity, in LL quadrants, the number of prefecture-level cities gradually increases from zero to four prefecture-level cities and then decreases to 1 prefecture-level cities, mainly Heyuan, Zhanjiang and Chaozhou in 2000 and 2005, an increase of two, mainly Jieyang and Shantou in 2014, only one prefecture-level city of Shantou, indicating that the low housing prices gradually to Guangdong In the $\mathrm{HH}$ quadrant, most of the $\mathrm{HH}$ quadrants were Zhongshan, Dongguan, Shenzhen and Zhuhai in 1995, mainly in Zhongshan, Dongguan, Guangzhou and Zhuhai in 2000, mainly in Zhongshan and Dongguan in 2005, Huizhou and Zhuhai decreased to two prefecture-level cities in 2010 and 2014, mainly in Dongguan and Zhuhai, indicating that there was a significant accumulation of high housing prices in the Pearl River Delta region and significantly higher housing prices in the surrounding areas of Dongguan and Zhuhai; the LH quadrant was mainly Huizhou and Zhongshan, indicating that housing prices in Huizhou and Zhongshan compared with the surrounding area is relatively low, and is very different with the surrounding areas in housing prices.Shantou changed from significant HL to significant LL quadrant, indicating that Shantou house prices tend from high to low, and the gap between Shantou and surrounding cities is gradually decreasing. This proves that housing prices in the Pearl River Delta are on the high side. However, the gap between cities in the Pearl River Delta region is gradually widening.

\subsection{Geographic Weighted Regression Analysis of House Prices in Guangdong Province (GWR)}

Based on the above analysis results, the price of housing in Guangdong Province shows obvious dualistic structure in space. The area with high housing price gradually gathers into the urban agglomeration formed by Shenzhen and Guangzhou. However, the gap between cities in the Pearl River Delta region has been gradually widened; Most of the cities in eastern Guangdong, western Guangdong and northern Guangdong have low prices and there is not much difference between the prices in cities, but the gap with the urban prices in the Pearl River Delta region is getting bigger and bigger. Thus, the spatial distribution of housing prices there are differences, first, because of their own geographical and immovable real estate, and second, with the economic growth of Guangdong Province cities, the degree of opening up and the process of urbanization and other factors, But also deepened the regional differences in housing prices. To explore the factors that lead to this difference, according to different factors on the impact of different prices in different cities and the spatial effect of different, to develop the corresponding regional real estate market development plan to achieve a reasonable adjustment of the structure of the real estate industry and the layout. 
Since the prices of cities in Guangdong Province show a significant spatial aggregation, not completely random distribution, if the traditional common least-squares method (OLS) analysis of the impact of price factors, neglecting the effect of space on housing prices and its impact factor The estimated results and inferences may not be reliable. Therefore, this paper uses the local weighted least squares method to introduce the spatial distance to establish the geographic weighted regression model (GWR) to analyze the influencing factors of house prices in 21 cities in Guangdong Province in 2005, 2010 and 2014, While the price of 21 cities in Guangdong Province showed a certain degree of diffusion in space. This obvious difference laid the foundation for the construction of GWR model (Table 3).

It shows that increasing the number of free parameters improves the goodness of fit. AIC encourages the goodness of data fitting, but tries to avoid over-fitting as far as possible. Therefore, the first model should be the one with the smallest AIC value. Because this paper has added two free parameters to compare and obtained three different results, the $\mathrm{R}^{2}$ of the three estimation results are all higher than $70 \%$. The smaller the AIC value is, the more reasonable the model estimation result will be. From the estimation results of GWR model, the local higher than $70 \%$, indicating that the GWR model has a higher fitting degree.

From the results of parameter estimation of each variable in each region, and comparing the regression coefficients of each explanatory variable, it is found that each explanatory variable has different impact on housing prices, and there are spatial differences, and the effect of the same variable on housing prices in different regions is more obvious. The effect of urbanization rate on housing prices is most obvious. On the right of Table 2, the urbanization rate and house price show a positive correlation, which shows that the increase of urbanization rate will promote the rise of house price, and the sensitivity of house price is the highest in Guangdong West, and the region gradually increased over time. The farther away from western Guangdong, the sensitivity to price impact gradually declines. The sensitivity of urbanization rates of Guangzhou, Shenzhen, Zhongshan and Dongguan to housing prices is moderate, mainly due to The rate of urbanization is high in these areas with a high level of development, and the rate of urbanization in some areas (such as Shenzhen) is $100 \%$ with almost no change. The left side of Figure 2 shows the positive correlation between GDP per capita and house prices, but the regression coefficient is not large. The sensitivity to house prices is relatively stable in 2005 and 2010, which has the

Table 3. Results of Table 1 2005, 2010, 2014 GWR model.

\begin{tabular}{cccc}
\hline Model parameter & 2005 & 2010 & 2014 \\
\hline Bandwidth & 71.419 & 71.419 & 71.419 \\
AICc & 359.445 & 391.823 & 397.873 \\
$R^{2}$ & 0.784 & 0.837 & 0.858 \\
Adjusted $R^{2}$ & 0.712 & 0.783 & 0.810 \\
\hline
\end{tabular}


greatest impact on house prices in eastern Guangdong. The farther away from eastern Guangdong, However, in 2014, on the contrary, GDP per capita had the highest price in western Guangdong, indicating that the impact of per capita GDP on housing prices was the largest among the two periods in 2010 and 2014. The distribution of urban population in cities and towns in Guangdong Province basically agrees with the level of regional housing prices. However, the distribution of population space usually goes through three stages. In the first stage, the population is shifting from rural areas to cities, and urban populations of different sizes are expanding and their shares of the total population are rising. This stage is related to the rapid economic growth and the rapid development of the manufacturing industry, while the urbanization rate has not yet reached 55\%. The second phase is mainly suburbanization. Growth in some small and medium-sized cities slowed down while the proportion of the population in the metropolitan areas continued to rise. This stage was accompanied by an absolute decline in manufacturing and the relative development of service industries. The corresponding level of urbanization is roughly between $55 \%-70 \%$. In the third stage, after the urbanization rate exceeded $70 \%$, the population continued to concentrate in the metropolitan area. The population growth of small and medium-sized cities was slow. The regional distribution structure of our country's population is in the second stage: the total volume is slowing down, the regional structure is being split, and people continue to migrate to the metropolis. In the initial stage of the development of the real estate market, the main driving factors are the rapid economic growth, rapid increase in resident income level, rapid urbanization rate and a large number of new home purchase demand. At the same time, the purchasing power of residents purchasing houses has risen rapidly. In the mid-term of the development of the real estate market, housing development has basically stabilized, and the correlation with the per capita GDP is no longer obvious, which is more affected by the urbanization rate and population migration.

Housing area in 2005 was negatively related to house prices in 2010 and 2014 was positively correlated with the price, but also the greatest impact on prices in western Guangdong Province, from the western Guangdong Province, the sensitivity of the impact of price gradually And it is the least sensitive to urban housing prices in the Pearl River Delta in 2014. This shows that the marginal effect of housing completion on housing prices is gradually increasing. The closer it is to the west of Guangdong, the greater the effect but the least effect on the PRD. The investment on the right side of real estate development is negatively correlated with the price of housing, and the impact on housing prices is larger, in line with the actual situation, which has the greatest inhibitory effect on housing prices in Meizhou, Chaozhou, Shantou and Jieyang, the role of the smallest. Loan balance has a positive correlation with house price. It is most sensitive to house price in western Guangdong, and the largest area gradually increases to the east direction, but its influence gradually decreases. It is the least sensitive to house price 
in eastern Guangdong, This shows that the effect of loan balance on housing prices gradually decreases from west to east. Housing completed area, real estate development investment and the short-term impact of loans on housing prices mechanism: the policy cut interest rates and mortgage down payment ratio, housing loans increased, residents pay ability, real estate sales rebound, real estate to the library, in short supply, housing prices, the development After the return of commercial funds to buy land, accelerating development and investment and expanding the completion of the area, the housing prices down.

\section{Conclusions and Discussion}

In the context of the central government's policy of "managing the city due to its classification and classification", the local government should regulate and control housing prices according to the differences in house prices among different cities. In order to study the evolvement and difference of house price in Guangdong Province, this paper takes the urban area of Guangdong Province as an economic unit and makes use of ESDA and GWR models to explore the spatial heterogeneity of house price in Guangdong Province in 1995-2014 and its influencing factors. The main conclusions are as follows:

First, judging from the trend chart and the space sub-plot of house prices, the regional differences of house prices have been gradually increasing in recent years, and the spatial structure of the area shows a certain stratosphere structure, that is, the Pearl River Delta region gathered, and the price difference between the Pearl River Delta cities gradually increased; eastern Guangdong, western Guangdong and northern most of the cities in the low prices, and the price difference between cities is not large, but with the Pearl River Delta region, the gap between the price of the city is very large. Overall, the size of the real estate market in Guangdong Province presents a bipolar aggregation phenomenon, and the difference in housing prices gradually increases.

Second, from the perspective of global autocorrelation, the price of prefecture-level cities in Guangdong Province tends to increase in the region as a whole. That is, housing prices are generally high around the high-price areas and low around the low-price areas. From the perspective of local autocorrelation, through the analysis of Moran's I scatter plot and LISA aggregation map, there is a clear spatial heterogeneity in the housing prices in all prefecture-level cities in Guangdong Province. The spatial differences are small and the housing price level tends to be high (high-high) in the area itself and the surrounding areas, mainly in the surrounding cities such as Dongguan and Zhuhai. Most of the areas with low level (low-low) are in eastern Guangdong; however, the area with the highest price (low-high) is mainly located in Huizhou and Zhongshan. The spatial difference is large and the house price is higher. However, the area with the lower surrounding price (high-low) is mainly located in Shantou.

Thirdly, from the factor of house price, per capita GDP and urbanization rate have a positive impact on house price over long period, but the impact of per ca- 
pita GDP on house price is much lower than that of urbanization. This shows that in the middle and late real estate development, house price and the per capita GDP are no longer obvious relevance, more affected by the rate of urbanization or population migration, and greater impact on western Guangdong. Housing completed area of housing prices has just begun to show a negative impact, and then showed a positive impact, the real estate development investment has a negative impact on housing prices, the loan balance has a positive impact on housing prices, these three factors are in the short cycle of price impact, housing completion area and loan balance are the most sensitive to the impact of urban house prices in western Guangdong. The former has the least effect on the Pearl River Delta. The latter has the least sensitivity to the price hikes in eastern Guangdong. The investment in real estate development is the most sensitive to urban prices in Meizhou, Chaozhou, Shantou, Jieyang housing prices generated the largest inhibition, the inhibition of the western part of the smallest. According to the impact of housing prices, there is a clear spatial heterogeneity in line with the use of "governance by the city, classification and control," the policy base for the rationality of the policy to provide a theoretical basis that different cities choose different tools for regulation and control, if you want to be in the long run, cities in western Guangdong consume stocks and accelerate the process of urbanization. If the city pulled up in the short term, urban prices in western Guangdong, expanding the completion of housing area, increase loan balance and reduce the real estate development investment to its greatest effect.

\section{References}

[1] Jiang, T.L., Bo, Z. and Zhi, G.H. (2012) Target Purchase Policy and the Dynamic Changes in Housing Prices. Economic Perspectives, 3, 47-54.

[2] Xian, Z.W. and Feng, J.Z. (2012) Fluctuation of House Prices and Financial Revenue: Transmission Mechanism and Empirical Analysis. Finance \& Trade Economics, 11, 21-28.

[3] Jiang, D. (2010) China's Real Estate Market Development Unbalance and Factor Analysis of Commercial Housing Prices. Journal of China University of Geosciences, 10-2, 93-97.

[4] Pollakowski, H.O. and Ray, T.S. (1997) Housing Price Diffusion Patterns at Different Aggregation Levels: An Examination of Housing Market Efficiency. Journal of Housing Research, 8-1, 107-124.

[5] Pede, V.O. (2011) Regional Housing Price Cycles: A Spatio-Temporal Analysis Using US State-Level Data. Working Papers, 45-5, 563-574.

[6] Zheng, X.T. and Li, Z. (2013) Spatial Effects of Housing Price Fluctuation: Estimation Methods and Empirical Evidence in China. Journal of Statistics and Management, 32-3, 401-413.

[7] Hai, Z.W., Xi, N.L. and Ling, Z. (2012) Effects of Urban Landscape on Residential Prices: A Case Study of Hangzhou. Geographic Research, 31-10, 1806-1814.

[8] Si, Q.Z., Huo, H. and Jing, C. (2011) Study on the Elastic Estimation of Urban Residential Carbon Emissions and Urban Discrepancy in China. Inquiry into Economic Issues, 9, 124-130. 
[9] He, W. (2012) Analysis of the Influencing Factors of Real Estate Prices Based on Spatial Measurement. Economic Review, 1, 48-56.

[10] Lang, N.C. and He, W. (2012) Empirical Study on Regional Interaction of Real Estate Prices in China. Statistical Research, 29-7, 37-43.

[11] Jian, R. and Feng, J.Z. (2014) Dynamic Mechanism of Spatial Correlation of House Prices: An Empirical Study Based on Spatial Durbin Model. China Real Estate, 1, 3-10.

[12] Ying, L. (2010) Spatial Heterogeneity and Regional Real Estate Price Fluctuation. Journal of Central University of Finance \& Economics, 11, 80-85.

[13] Qing, Y.T., Wei, X. and Fu, L.A. (2012) Study on the Spatial Differentiation of Shanghai Housing Price and Its Influence Factors Based on Geographic Weighted Regression. Economic Geography, 32-2, 52-58.

[14] Zhen, N.Y. and Ci, F.W. (2016) Spatial Characteristics and Influential Factors of Land Urbanization in Zhejiang Province Based on ESDA-GWR. China Land Sciences, 30-3, 29-36.

[15] Ya, J.Z., Hai, J., Xing, G. and Liang, Q.Y. (2015) Shao Qingjun Economic Spatial Pattern Evolution Based on Multivariable Effects of ESDA-GWR. Scientia Geographica Sinica, 3, 28-35.

[16] Jing, Z., Li, F.Z., Li, J.Z. and Chi, M.G. (2012) Spatial-Temporal Evolution of Urban Residential Land Prices Based on GWR Model. Geography Science, 7, 828-834.

[17] Zhi, Z.D., Hao, G. and Yan, M. (2010) Analysis of Factors Influencing Real Estate Price: An Empirical Study Based on Panel Data of Different Provinces and Cities in China. Journal of China University of Geosciences, 10-2, 98-103. 